\title{
KAJIAN KELEMBAGAAN DALAM PENERAPAN SISTEM ONLINE MONITORING KUALITAS AIR SUNGAI CILIWUNG
}

\author{
Nugro Rahardjo dan Taty Hernaningsih \\ Pusat Teknologi Lingkungan, BPPT, Kawasan Puspiptek, Tangerang Selatan, 15314, Indonesia \\ E-mail: nugro.rahardjo@bppt.go.id ; tati.hernaningsih@bppt.go.id
}

\begin{abstract}
ABSTRAK
Menurunnya kualitas air Sungai Ciliwung dan rendahnya kemampuan pemurnian diri (self purification), memerlukan pengelolaan yang menyeluruh. Upaya - upaya telah banyak dilakukan untuk mengatasi berbagai permasalahan Sungai Ciliwung yang sangat kompleks tersebut. Berbagai instansi pemerintah, baik dari tingkat pusat, lokal dan bahkan masyarakat yang peduli kepada Sungai Ciliwung telah melakukan berbagai program dan kegiatan-kegiatan terpadu dalam pengelolaan Sungai Ciliwung, namun memang permasalahannya sangat berat, sehingga dibutuhkan kesungguhan dan waktu yang lama untuk dapat memulihkan Sungai Ciliwung. Salah satu program yang diperuntukkan bagi Sungai Ciliwung adalah Pengkajian aplikasi teknologi Online Monitoring untuk kualitas air yang ditujukan untuk mengendalikan dan memantau tingkat pencemaran air Sungai Ciliwung. Dalam pelaksanaan program dibutuhkan persiapan yang matang, terutama dalam koordinasi kelembagaan untuk pengelolaan sistem tersebut. Sesuai dengan program ini maka dilakukan penelitian untuk mendapatkan informasi terkait status kelembagaan DAS Ciliwung dan menempatkan sistem Online Monitoring dalam sistem kelembagaan yang sudah ada. Pembahasan ini meliputi penerapan koordinasi sistem pengendalian pencemaran DAS Ciliwung, permasalahan online monitoring dan alternatif pemecahannya.
\end{abstract}

Kata kunci: Koordinasi, Kelembagaan, Online Monitoring

\section{STUDY OF INSTITUTION IN THE IMPLEMENTATION OF THE WATER QUALITY MONITORING SYSTEM OF CILIWUNG RIVER}

\author{
Nugro Rahardjo and Taty Hernaningsih \\ Center for Environmental Technology, BPPT, Puspiptek Area, South Tangerang, 15314, Indonesia \\ E-mail: nugro.rahardjo@bppt.go.id ; tati.hernaningsih@bppt.go.id
}

\begin{abstract}
The water quality decreasing of the Ciliwung River and low self-purification capabilities require comprehensive management. Efforts have been made to address the complex issues of the Ciliwung River. Various government agencies, both from the central, local and even people who care for the Ciliwung River have conducted various programs and integrated activities in the Ciliwung River management, but the problem is very heavy, so it takes a long time to recover the Ciliwung River. One of the programs devoted to the Ciliwung River is the Technology Application of Online Monitoring. It is monitoring for water quality aimed at controlling and monitoring Ciliwung River water pollution levels. The implementation of the program requires careful preparation, especially in coordinating the management of the system institutionally. In accordance with this program, research is conducted to obtain many informations related to the institutional status of the Ciliwung watershed and to place an online monitoring system within an existing institutional system. This discussion covers the application of coordination for pollution control system in Ciliwung watershed, online monitoring problem and some alternatives as the solutions.
\end{abstract}

Keywords : Coordination, Institutional, Online Monitoring 


\section{PENDAHULUAN}

Sebagai salah satu sumber daya air yang potensial Sungai Ciliwung mempunyai peran yang sangat penting bagi warga Jakarta dan sekitarnya. Peran tersebut ialah baik sebagai pemasok air maupun sebagai penjaga keseimbangan sistem akuifer di daerah aliran sungai (DAS) Ciliwung sesuai dengan proses dan siklus hidrologinya. Dari hulu hingga hilir Sungai Ciliwung memberi manfaat yang sangat besar, misalnya merupakan fungsi utama dalam sistem irigasi di sektor pertanian, dan sebagai sumber air baku bagi masyarakat, PDAM dan industri dalam pemenuhan kebutuhan air bersih atau air minum, serta sekaligus sebagai saluran primer penampung dari seluruh drainase perkotaan.

Begitu banyaknya pemanfaatan Sungai Ciliwung untuk berbagai kepentingan yang seolah tidak terbatas itu dalam bertumbuh-kembangnya kota, khususnya Bogor dan Jakarta, maka permasalahan yang timbul akan terus semakin kompleks. Permasalahan utama yang jelas terlihat adalah menurunnya kualitas air Sungai Ciliwung dan rendahnya kemampuan pemurnian diri (self purification), karena pencemaran lingkungan yang disebabkan tidak terkendalinya air limbah domestik, industri atau bahkan dari area pertanian dan peternakan yang mengalir masuk ke dalam Sungai Ciliwung. Permasalahan Sungai Ciliwung tidak hanya pada kualitas, tetapi juga pada kuantitasnya. Penataan lingkungan perkotaan dan pemanfaatan lahan yang belum berorientasi penuh kepada konsep ramah lingkungan menyebabkan semakin terbatasnya daya tampung dan daya lenting Sungai Ciliwung terutama pada musim hujan, sehingga yang terjadi adalah bencana banjir di DAS Sungai Ciliwung dan sekitarnya.

Upaya - upaya telah banyak dilakukan untuk mengatasi berbagai permasalahan Sungai Ciliwung yang sangat kompleks tersebut. Berbagai instansi pemerintah, baik dari tingkat pusat, lokal dan bahkan masyarakat yang peduli kepada Sungai Ciliwung telah melakukan berbagai program dan kegiatan-kegiatan terpadu dalam pengelolaan Sungai Ciliwung, namun memang permasalahannya sangat berat, sehingga dibutuhkan kesungguhan dan waktu yang lama untuk dapat memulihkan Sungai Ciliwung yang sedang "sakit" ini. 3 Program terkini yang diperuntukkan bagi Sungai Ciliwung adalah (1) Restorasi Sungai dengan memilih lokasi percontohan di ruas Mesjid Agung Istiqlal, (2) Normalisasi Sungai Ciliwung sepanjang $19 \mathrm{~km}$ dari mulai jalan Tol Lingkar Selatan hingga pintu air Manggarai, dan (3) Pengkajian aplikasi teknologi Online Monitoring untuk kualitas air.

Program Restorasi Sungai Ciliwung memang selayaknya dilakukan secara utuh dari hulu ke hilir dan program ini lebih tertuju pada peningkatan kualitas air sungai, sementara itu program normalisasi sungai lebih ditujukan pada penataan dan peningkatan sungai berkaitan dengan penanggulangan banjir. Program yang terakhir (ketiga) lebih ditujukan pada maksud untuk mengendalikan dan memantau tingkat pencemaran air Sungai Ciliwung. Program ini sangat membutuhkan persiapan yang matang, terutama dalam koordinasi kelembagaan. Untuk itu diperlukan suatu kajian lebih komprehensif guna melihat keterkaitan berbagai instansi pemerintah maupun NGO dan pembagian tugas dalam penerapan dan pengelolaan sistem teknologi Online Monitoring tersebut.

\section{TUJUAN DAN SASARAN}

Tujuan dari kajian ini adalah untuk
mendapatkan kelembagaan DAS Ciliwung dan menempatkan sistem online monitoring dalam sistem kelembagaan yang sudah ada.

Sasaran dari kajian ini adalah diperolehnya informasi status kelembagaan DAS Ciliwung terkini dan rekomendasi penerapan sistem kelembagaan penerapan dan pengelolaan online monitoring yang efektif mulai dari penentuan lembaga pengelola sistem online monitoring, penentuan persyaratan kelembagaan, manajemen kelembagaan, perizinan penempatan alat online monitoring serta sepintas kajian perundang-undangan yang berlaku dan berkaitan dengan kelembagaan.

\section{RUANG LINGKUP}

Ruang lingkup dari kajian kelembagaan sistem online monitoring DAS Ciliwung adalah pemahaman umum DAS Ciliwung, kebijakan yang diambil di daerah hulu dan aktivitas yang menjadikan penurunan kualitas air, baik di daerah hulu maupun di daerah hilir. Namun kajian kebijakan akan dititikberatkan pada daerah hilir khususnya segmen 5 dan 6 Sungai Ciliwung mengingat terjadinya pencemaran di daerah hilir (kota Jakarta) sangat tinggi dan sangat mengkhawatirkan.

\section{METODOLOGI}

Metodologi kajian kelembangaan sistem online monitoring DAS Ciliwung adalah dengan melakukan studi literature, survei kelembagaan dengan cara menggali informasi dan kebijakan yang dikeluarkan oleh otoritas pemerintah baik pusat maupun daerah khususnya DKI Jakarta, dan Focus Group Discussion, serta wawancara langsung dengan para pengambil keputusan terkait dengan penempatan sistem online monitoring di DAS Ciliwung. Hasil dari semua kegiatan di atas dianalisa secara deskriptif dan saling keterkaitan antar unsur disintesiskan dan 
dikomunikasikan untuk mendapatkan persetujuan dari pihak-pihak pengambil keputusan yang akan menghasilkan sejumlah rekomendasi dan paket roadmap dan tahapan pelaksanaan penempatan sistem online monitoring.

\section{KELEMBAGAAN PENGELOLA SISTEM ONLINE MONITORING}

\subsection{Regulasi / Perundang-Undangan dan Tupoksi Kelembagaan}

Regulasi / perundang-undangan yang berkaitan dengan pemantauan kualitas dan kuantitas serta pengelolaan sumber air adalah Undang-Undang Republik Indonesia No.7 Tahun 2004 Tentang Sumberdaya Air, Peraturan Presiden Nomor 33 tahun 2011 tentang Kebijakan Nasional Pengelolaan Sumberdaya Air, Peraturan Pemerintah Republik Indonesia No. 38 Tahun 2011 tentang Sungai, Peraturan Pemerintah No. 42 Tahun 2008 Tentang Pengelolaan Sumberdaya Air. Undang-Undang Republik Indonesia No.7 Tahun 2004 Tentang Sumberdaya Air sayangnya telah dicabut dan mungkin akan disempurnakan lagi.

Tupoksi Kelembagaan yang berhubungan dengan pemantauan kualitas dan kuantitas serta pengelolaan sumber air terdapat pada Direktorat Jenderal Sumber Daya Air Kementerian PU, Balai Besar Wilayah Sungai Ciliwung-Cisadane Kementerian PU, Kementerian Lingkungan Hidup, Pusat Sarana Pengendalian Dampak Lingkungan (Pusarpedal), Badan Perencanaan dan Pembangunan Daerah (Bappeda) Provinsi DKI Jakarta, Dinas Pekerjaan Umum Provinsi DKI Jakarta dan Badan Pengelola Lingkungan Hidup Daerah (BPLHD) Provinsi DKI Jakarta,

\subsection{Penerapan Koordinasi Sistem Pengendalian Pencemaran DAS Ciliwung \\ Untuk mengatur dan mengarahkan perilaku stakeholders yang terlibat dalam pengelolaan DAS perlu suatu kelembagaan. Menurut Soekanto (1999) fungsi kelembagaan adalah: 1) sebagai pedoman bagi masyarakat untuk bertingkah laku, 2) menjaga keutuhan masyarakat dan 3) sebagai sistem pengendalian sosial (social control), artinya sistem pengawasan dari masyarakat terhadap tingkah laku anggotanya.}

Ada beberapa alternatif bentuk penguatan kelembagaan dalam pengelolaan DAS, antara lain:

a. membentuk kepengurusan kolaboratif

b. membentuk lembaga baru

c. memanfaatkan lembaga yang sudah ada.

Membentuk kepengurusan kolaboratif dalam bentuk forum atau badan koordinasi merupakan salah satu alternatif yang paling memungkinkan dalam penguatan kelembagaan pengelolaan DAS saat ini. Pernyataan tersebut didukung oleh beberapa kondisi antara lain:

a. Sesuai dengan perundang-undangan yang ada (dulu UU No 7 tahun 2004).

b. Kegiatan pengelolaan DAS melibatkan banyak stakeholders lintas sektoral, multidisiplin dan lintas wilayah, oleh karena itu kelembagaan yang disusun hendaknya kelembagaan yang bersifat independen dan mewakili banyak pihak.

c. Permasalahan yang paling menonjol dalam pengelolaan DAS saat ini adalah koordinasi. Oleh karena itu pengelolaan DAS ke depan perlu suatu wadah yang mengikat, menyatukan dan menyelaraskan semua sektor dan wilayah agar dapat mewujudkan pengelolaan DAS yang berkelanjutan.

Kata koordinasi telah sering kita dengar yang menjadi cara menuju tercapainya sinergi pelaksanaan kegiatan, tapi dalam prakteknya hal tersebut tidak mudah dilaksanakan. Ada empat tahapan alamiah yang berjenjang menuju koordinasi yaitu; 1) terhubung (connected), 2) berkomunikasi (communicated), 3) bekerja sama (collaborated) dan, 4) berkoordinasi (coordinated). Derajat sofistikasi pada setiap tahapan dapat meningkat dari yang konvensional menjadi lebih maju (advanced). Berkembang-pesatnya teknologi komunikasi dan informatika (TIK) telah mempercepat aliran data dan informasi untuk koordinasi pengelolaan sungai Ciliwung yang lebih baik.

Tabel berikut menggambarkan proses alamiah yang terjadi pada 2 (dua) pihak yang akan bekerja sama.

Tabel 1: Tahapan Alamiah Menuju Koordinasi Sinergistik

\begin{tabular}{|l|l|l|l|}
\hline \multicolumn{1}{|c|}{ Tahapan } & \multicolumn{1}{c|}{ Awal } & \multicolumn{1}{c|}{ Proses } & \multicolumn{1}{c|}{ Advanced } \\
\hline Connected & Mengetahui & Berkenalan & Bertukar alamat kontak \\
\hline Communicated & Info sharing & Diskusi interaktif & Muncul 'trust' \\
\hline Collaborated & Bertukar ide atau alat bersama & Setuju bekerjasama & Melakukan kegiatan bersama \\
\hline Co-ordinated & Sepakat prosedur standar (SOP) & Evaluasi bersama & Bersinergi \\
\hline
\end{tabular}

Sumber: DRN, 2010 
Untuk itu, indikator-indikator kualitatif bagi terbentuknya koordinasi perlu terus dikembangkan yaitu: [1] kelembagaan: hubungan lembaga litbang dengan perangkat struktural, dukungan pimpinan lembaga; [2] infrastruktur: jaringan internet dan situs web, pengelola formal; [3] kesiapan berkomunikasi: pertemuan rutin, pertukaran data/informasi secara teratur, wahana interaksi (ruang bersama); [4] kesiapan SDM: komunitas pelaku riset yang aktif dan unit khusus yang menangani aspek komunikasi.

\subsection{Sistem Online Monitoring Kualitas Air Sungai Ciliwung}

Dengan adanya rencana pemasangan sistem online monitoring kualitas air sungai Ciliwung yang bersifat real time, maka diperlukan koordinasi di antara para pemangku kepentingan baik di tingkat pemerintah pusat maupun provinsi DKI Jakarta dan kota. Untuk memastikan bahwa sistem online monitoring berjalan dengan baik maka koordinasi internal para insinyur dan teknisi pencipta sistem tersebut harus mendapat perhatian yang utama, karena apabila sistem perekamannya tidak dapat berjalan dengan baik, maka akan terjadi permasalahan yang serius dengan tidak didapatkannya data parameter kualitas lingkungan yang diharapkan.

Selanjutnya data yang diperoleh tersebut direkomendasikan agar dapat disajikan sampai pada tingkatan analisis dan model yang mudah dipahami pesannya, sehingga sistem alert yang direncanakan dapat bekerja dengan baik agar tidak menimbulkan salah interpretasi bagi yang membacanya. Untuk selanjutnya dikomunikasikan lebih lanjut kepada masyarakat dalam bahasa yang mudah dipahami.

\subsection{Sistem Finansial}

Sistem finansial yang dimaksud disini lebih mengarah kepada pendanaan dalam penerapan dan pengelolaan sistem online monitoring. Sistem finansial ini erat kaitannya dengan sistem peraturan dan perundang - undangan, yang sampai saat ini dapat dikatakan sudah memadai. Memang dibutuhkan penyempurnaan terhadap Undang-Undang No. 7 tahun 2004 tentang sumber daya air yang antara lain sudah mempunyai tujuan untuk memberi dasar hukum yang kuat dalam hal kewenangan lembaga atau instansi yang ditunjuk untuk pengelolaan sistem online monitoring tersebut. Hal ini sangat dibutuhkan guna menjamin agar keberkelanjutan (sustainability) sistem online monitoring dapat dioperasikan secara terus-menerus. Sistem pendanaan online monitoring dibebankan pada anggaran $\mathrm{KLH}$ namun selanjutnya pendanaan teknisnya disarankan dibebankan ke BPLHD Provinsi DKI Jakarta.

\subsection{Sistem Pengoperasian}

Sistem pengoperasian disarankan dilakukan oleh salah satu unit yang sekarang sudah ada di BPLHD, namun dibutuhkan penganggaran secara rutin yang memadai. Selanjutnya perlu dibentuk suatu tim yang kompeten melakukan pengoperasiannya. Pengembangan Capacity Building perlu diberikan kepada tim pengoperasian agar mendapatkan bekal yang cukup dan profesional dalam pengelolaan sistem tersebut.

\subsection{Sistem Pengamanan}

Sistem pengamanan online monitoring perlu dilakukan bersama-sama masyarakat sekitar penempatan online monitoring dan bekerjasama dengan aparat keamanan setempat. Sistem pengamanan ini merupakan salah satu faktor kunci keberhasilan segala macam program lapangan apapun termasuk pemasangan online monitoring.

\subsection{Sistem Peran Serta Masyarakat}

Peran serta masyarakat merupakan hal yang sangat penting dalam pemahaman yang baik tentang tata cara pengoperasian online monitoring, maupun dalam pengelolaannya secara berkelanjutan. Data online monitoring hendaknya dikemas menjadi informasi yang sudah melalui analisa dan disajikan menjadi informasi yang bermanfaat terkait kualitas air Ciliwung. Oleh karena itu perlu dibentuk dan diperkuat sistem kemasyarakatan yang mendukung aktivitas terkait online monitoring di masyarakat.

\subsection{Struktur Organisasi Sistem Online Monitoring Sungai Ciliwung}

Untuk pelaksanaan pemantauan kualitas air sungai Ciliwung secara online, maka diperlukan struktur organisasi yang berada di institusi pemerintah yang mempunyai tugas pokok dan fungsi terkait. Sesuai hasil kajian ini direkomendasikan BPLHD DKI Jakarta sebagai institusi yang dapat melakukan pengelolaan dan operasional sistem online monitoring ini. Struktur organisasi yang diperlukan adalah sebagai berikut: 


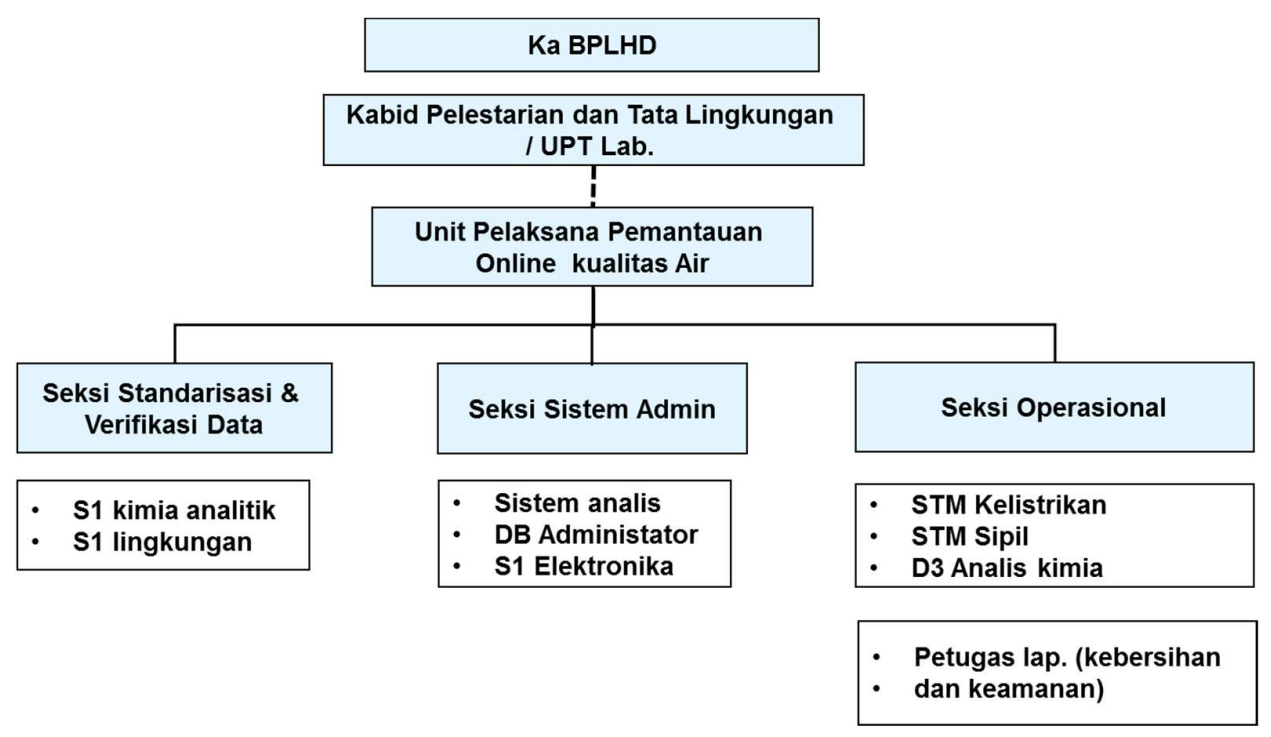

Gambar 1: Struktur Organisasi Pengelola Sistem Online Monitoring

Tugas Unit Pelaksana Pemantauan Online Kualitas Air maupun seksi-seksi dibawahnya adalah sebagai berikut:

a. Mengkoordinasikan tugas pemeliharaan sistem hardware dan software secara rutin.

b. Melakukan koordinasi dengan unit lain dan masyarakat di luar instansi terkait dengan kegiatan online monitoring.

c. Melaporkan hasil kegiatan pemantauan baik secara manual maupun online secara rutin.

d. Menjamin tersedianya perangkat pendukung hardware dan software jika diperlukan untuk pengoperasian sistem hardware dan software online monitoring.

\section{PERMASALAHAN ONLINE MONITORING DAN ALTERNATIF PEMECAHANNYA}

\subsection{Isu-isu Terkini Terkait DAS Ciliwung}

Gubernur DKI Jakarta telah melakukan peninjauan dan koordinasi dengan aparat terkait dan pihak keamanan telah merencanakan untuk pembangunan sungai Ciliwung menjadi wilayah ekoturisme. Tentunya hal ini merupakan tantangan yang sangat berat mengingat kualitas air dan lingkungan sungai Ciliwung sangatlah buruk saat ini.

Balai Besar Wilayah Sungai Ciliwung dan Cisadane (BBWSCC) telah melakukan normalisasi di beberapa segmen untuk meningkatkan debit aliran sungai antara jalan TB Simatupang-Manggarai.

Hal ini sudah sangat tepat mengingat perlunya kemampuan untuk menampung penambahan debit aliran sungai, misalnya dalam mengatasi sebagian banjir Jakarta.

Terkait dengan hal ini penempatan bangunan sistem online monitoring harus mendapatkan persetujuan oleh tim rekomendasi teknis BBWSCC untuk selanjutnya diterbitkan surat ijin pembangunan konstruksi pelindung sistem online monitoring.

Pihak BPLHD selaku institusi di bawah pemerintah provinsi DKI Jakarta akan menerima dengan senang hati apabila diberi hibah untuk operasionalisasi sistem online monitoring di Sungai Ciliwung. Namun pada saat serah terima harus sudah jelas status alat ini. Hal ini terkait dengan peraturan pemerintah mengenai aset antara pemerintah pusat yang dalam hal ini Kementerian LH dan Kehutanan dan pemerintah provinsi DKI Jakarta (BPLHD). Untuk itu perlu ditanyakan dan diklarifikasi ke pihak kementerian keuangan terutama di bagian perbendaharaan Negara tentang aturan-aturan yang berlaku. Oleh karena itu harus jelas prosedurnya.

Pengalaman buruk BPLHD dalam monitoring emisi karbon di perkotaan di Indonesia, yaitu pengelolaan dan perawatan peralatan tersebut mengalami kendala karena tidak jelasnya status asetnya. Pada kenyataannya BPLHD tidak boleh mengajukan anggaran untuk peralatan yang bukan asetnya.

Dinas Pekerjaan Umum Pemerintah Provinsi DKI Jakarta telah melakukan pemasangan automatic water level recorder (AWLR) sejumlah titik di sepanjang sungai Ciliwung. AWLR ini difungsikan sebagai pengukur ketinggian air sungai dan pengukur debit air yang melewati titik itu, sehingga diharapkan dapat memberikan informasi kepada pemangku kepentingan dalam mengambil keputusan terkait bencana banjir yang akan melanda Jakarta dan sekitarnya. Secara kelembagaan tugas pemantauan daya rusak air ini menjadi tanggung jawab Kementerian PU dan dinas-dinas terkait. 
Isu keamanan peralatan online monitoring menjadi sangat krusial mengingat harga alat ini yang cukup mahal, dan apabila sampai terjadi kehilangan maka dapat dipastikan tidak dapat merekam data kualitas air sampai adanya alat baru untuk dipasang kembali. Selain kenyataan tersebut di atas, direncanakan tahun ini akan dibangun pompa air di pintu pantai MarinaAncol sebanyak 10 (sepuluh) pompa dengan kapasitas $10 \mathrm{~m}^{3} /$ detik oleh Dinas Pekerjaan Umum Provinsi DKI Jakarta.

Kebijakan penempatan sistem online monitoring juga sejalan dalam perspektif pengembangan Teluk Jakarta ke depan dengan adanya rencana pembangunan Giant Sea Wall pada proyek NCICD (National Capitai Integrated Coastal Development). Artinya kebijakan yang diambil dalam penempatan sistem online monitoring harus mempertimbangkan keselarasan dengan kebijakan NCICD.

\subsection{Implikasi Kebijakan}

Dengan akan dipasangnya sistem online monitoring di sungai Ciliwung maka diharapkan adanya kebijakan-kebijakan baik tingkat pusat maupun pemerintah provinsi DKI Jakarta yang memacu baik masyarakat, industri, maupun fasilitas-fasilitas umum seperti rumah sakit, gedung pertemuan juga perkantoran untuk mendukung dan menjaga kualitas air sungai Ciliwung.

Selain berfungsi sebagai early warning sistem (EWS), online monitoring dapat difungsikan sebagai alat untuk menekan pihakpihak yang membuang limbah ke badan air agar meminimalkan buangan limbah baik secara kuantitas maupun kualitas. Hal ini lebih bersifat preventif, yaitu meminimalkan buangan limbah ke badan air dari pada membersihkannya, karena biaya yang diperlukan untuk membersihkan biasanya jauh lebih mahal dibandingkan dengan usaha mengurangi limbah itu sendiri.

\subsection{Pendapat dan Saran Pakar-Pakar (Dalam sesi FGD)}

Pendapat dan saran berasal dari Kelembagaan DAS Ciliwung, yaitu:

a. Kementerian terkait lingkungan DAS: KemPU, KLHK, Kemtan, \& Kemkes.

b. Balai Besar Wilayah Sungai Ciliwung Cisadane, KemPU. c. Pusat Sumberdaya Air, KemPU.

d. Pemda Jabardan Pemda DKI Jakarta (Dinas PU Provinsi DKI).

e. BPLHD

f. Kemhut: Deputi DAS, BP DAS CitarumCiliwung, NGO dsb.

Hasil diskusi cenderung menyimpulkan untuk masalah kelembagaan tidak perlu dilakukan pembentukan badan khusus hanya saja dibutuhkan koordinasi seperti FGD atau konsorsium.

\subsection{Monitoring Kebijakan dan Rencana Evaluasi \\ Diharapkan dengan dipasangnya sistem} online monitoring ke depan yang berfungsi sebagai alert system, akan ada kebijakankebijakan baru yang timbul. Kebijakan-kebijakan yang akan timbul tersebut harus diikuti evaluasi dan perbaikan agar menghasilkan kebijakan yang unggul dalam mengatasi sungai Ciliwung dan untuk perbaikan system, baik teknis maupun kelembagaan yang sudah ada.

\subsection{Pertimbangan Kesesuaian Institusi Pengelola Sistem Online Monitoring dan Proses Perijinan}

\section{a. Matriks Kesesuaian Operasional Sistem Online Monitoring S. Ciliwung} Dalam kajian ini dilakukan melalui pendekatan kualitatif yang sering disebut dengan naturalistic inquiry. Apapun macam, cara atau corak analisis data kualitatif sua tu penelitian, tahap awal yang dilakukan adalah membaca fenomena. Setiap data kualitatif mempunyai karakteristiknya sendiri dan data kualitatif secara tersirat di dalam sumber datanya. Sumber data kualitatif adalah catatan hasil observasi, transkrip interviu mendalam (depth interview), dan dokumen - dokumen terkait berupa tulisan ataupun gambar.

Berdasarkan analisis data diperoleh matriks kesesuaian institusi pengelola sistem online monitoring sebagai berikut (Lihat Tabel 2):

Tabel 2: Matriks kesesuaian institusi pengelola sistem online monitoring

\begin{tabular}{|l|c|c|c|}
\hline & BPLHD & DINAS PU & PUSARPEDAL \\
\hline Kesiapan & $* * * *$ & $* * *$ & $* * *$ \\
\hline Keamanan & $* *$ & ${ }^{* * *}$ & ${ }^{*}$ \\
\hline SDM & $* * *$ & ${ }^{* * *}$ & ${ }^{* *}$ \\
\hline Command Center & $* *$ & $* * *$ & ${ }^{* *}$ \\
\hline
\end{tabular}




\begin{tabular}{|l|c|c|c|}
\hline & BPLHD & DINAS PU & PUSARPEDAL \\
\hline Pengolahan Data & $* * *$ & ${ }^{* * *}$ & $* *$ \\
\hline Analisis Data & $* * *$ & ${ }^{* * *}$ & $* * *$ \\
\hline Identifikasi Pengguna & $* * *$ & $* * *$ & $* * *$ \\
\hline Masukan Kebijakan & $* * * *$ & $* * *$ & $* * *$ \\
\hline
\end{tabular}

Keterangan: ${ }^{* * * *}=$ sangat tinggi, ${ }^{* * *}=$ tinggi, ${ }^{* *}=$ sedang, ${ }^{*}=$ kurang

Tabel 3: Saran Pengelola Sistem Online Monitoring

\begin{tabular}{|c|c|c|c|}
\hline No & INSTITUSI & KENDALA & SARAN CARA MENGATASI \\
\hline 1. & BLHD & $\begin{array}{l}\text { - Belum adanya unit khusus } \\
\text { yang menangani sistem } \\
\text { online monitoring. } \\
\text { - Belum tersedianya komputer } \\
\text { hardware } \\
\text { - Pengalaman sebelumnya } \\
\text { sistem online monitoring yang } \\
\text { diinstall tidak berjalan sesuai } \\
\text { rencana. }\end{array}$ & $\begin{array}{l}\text { - Unit kerja struktural lebih disukai } \\
\text { namun apabila tidak memungkinkan } \\
\text { dapat dilakukan penugasan kepada staf } \\
\text { yang kompeten. } \\
\text { - Pengadaan komputer hardware. } \\
\text { - Peningkatan kapasitas operasional dan } \\
\text { pemeliharaan sistem online monitoring }\end{array}$ \\
\hline 2. & Dinas PU & $\begin{array}{l}\text { - Lebih berfungsi penyediaan } \\
\text { data terkait kuantitas air sungai } \\
\text { Ciliwung } \\
\text { - Command Center belum } \\
\text { berfungsi dengan baik } \\
\text { - Belum punya pengalaman } \\
\text { jaringan dengan pengguna data } \\
\text { kualitas air }\end{array}$ & $\begin{array}{l}\text { - Penambahan fungsi monitoring selain } \\
\text { kuantitas tapi juga kualitas air sungai } \\
\text { Ciliwung } \\
\text { - Perlu danya penguatan di sistem dan } \\
\text { pembangunan kapasitas SDM } \\
\text { - Membangun jaringan dan identifikasi } \\
\text { pengguna, baik industri, rumah sakit } \\
\text { ataupun masyarakat }\end{array}$ \\
\hline 3 & Pusarpedal & $\begin{array}{l}\text { - Fokus kegiatan lebih } \\
\text { sebagai pusat rujukan } \\
\text { laboratorium lingkungan } \\
\text { nasional. } \\
\text { - Belum tersedianya komputer } \\
\text { hardware. } \\
\text { - Jaringan pengguna data } \\
\text { kualitas air sungai Ciliwung } \\
\text { masih terbatas }\end{array}$ & $\begin{array}{l}\text { - Mengarahkan SDM dan fasilitas untuk } \\
\text { fokus ke restorasi sungai Ciliwung } \\
\text { - Pengadaan komputer hardware } \\
\text { - Membangun jaringan dan identifikasi } \\
\text { pengguna baik industri, rumah sakit } \\
\text { maupun masyarakat }\end{array}$ \\
\hline
\end{tabular}

b. Proses Pengajuan Perijinan Sistem Online Monitoring

Untuk mendapatkan ijin penempatan sistem online monitoring di badan sungai Ciliwung, maka diperlukan ijin dari pihak yang berwenang. Dalam hal ini Balai Besar Wilayah Sungai Ciliwung-Cisadane merupakan institusi yang memproses pengeluaran ijin tersebut. Gambar 2 menyajikan proses pengajuan perijinan tersebut.

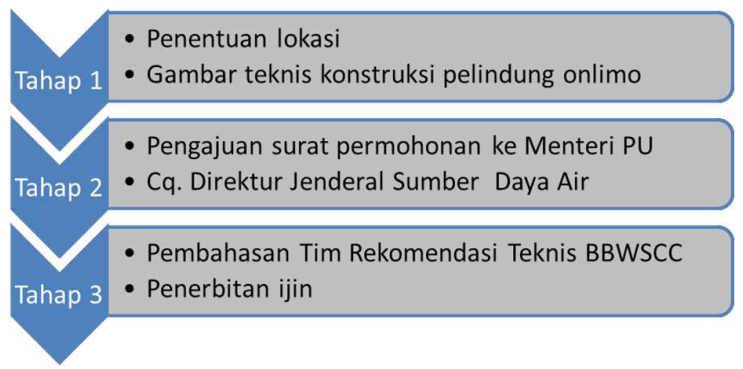

Gambar 2: Proses pengajuan perijinan sistem online monitoring ke BWSCC

\section{KESIMPULAN DAN SARAN}

Dari uraian di atas maka dapat disimpulkan bahwa sudah adanya sistem perundangan dan peraturan pemerintah sebagai payung (landasan) penempatan sistem online monitoring di Sungai Ciliwung. Pada tataran regulasi di bawahnya perlu 
adanya pasal khusus yang mengikat terkait online monitoring sungai yang menyangkut tugas pokok dan fungsi sebagai unit kerja pada suatu institusi. Sistem online monitoring dapat dipakai sebagai instrumen pengendali pencemaran lingkungan dengan dukungan dari berbagai pihak terkait.

Berikut ini adalah beberapa rekomendasi, yaitu

a. Sistem online monitoring sungai Ciliwung sangat diperlukan namun perlu disiapkan sistem kelembagaan yang handal. Sistem kelembagaan ini dapat dipersiapkan sedini mungkin agar tujuan dari pemasangan sistem online monitoring ini dapat berjalan dengan baik.

b. Pentingnya teknologi online monitoring ini diperlukan mengingat cakupan lokasi sungai dan daerah tercemar lainnya sangat luas, sehingga tidak memungkinkan dilakukan secara manual yang mengandalkan SDM institusi yang ada dengan jumlahnya yang sangat terbatas, sedangkan perkembangan kota metropolitan diprediksi semakin kompleks.

c. Walaupun sudah ada perundangan dan peraturan pemerintah sebagai payung (landasan) penempatan sistem online monitoring di Sungai Ciliwung, namun pada tataran regulasi dibawahnya perlu adanya tambahan pasal-pasal atau Perda yang mengikat disertai dengan sanksi yang ditegakkan apabila terjadi pelanggaran.

d. Sistem online monitoring dapat dipakai sebagai instrument pengendali pencemaran lingkungan dengan dukungan dari berbagai pihak terkait. Direkomendasikan penggunaan sistem online monitoring diarahkan ke lokasi instalasi pengolah air limbah yang dimiliki oleh setiap industri maupun rumah sakit dan sumber pencemar lainnya.

e. BPLHD cq. Bidang Pelestarian dan Tata Lingkungan adalah kandidat utama sebagai institusi pengelola Online monitoring karena memenuhi persyaratan yang diperlukan dan sangat sesuai dengan tugas pokok dan fungsinya. Kekurangan yang ada diharapkan dapat ditutupi dengan cara learning by doing.

f. Dinas PU Provinsi DKI Jakarta dapat dijadikan alternatif sebagai kandidat pengelola sistem online monitoring dengan pertimbangan kesiapan institusi tersebut dengan telah dioperasikannya sejumlah Automatic Water Level Recording (AWLR) dan Closed Circuit Television (CCTV) untuk pemantauan debit dan ketinggian air di sungai Ciliwung. Selain institusi tersebut sudah mempunyai pengalaman dalam pengamanan sistem peralatan yang dipasang. Command Center juga sudah diinisiasi untuk pusat kendali lapangan dari penentu kebijakan.

g. Pusarpedal juga mempunyai peluang yang tinggi untuk dapat mengelola dan mengoperasikan sistem online monitoring, namun kenyataannya kewenangan pemantauan kualitas air sungai Ciliwung lebih ke Pemerintah Provinsi DKI Jakarta. Sedangkan tugas pokok dan fungsi kewenangan Pusarpedal lebih bersifat nasional, sehingga dalam jangkauan wilayah monitoring kualitas air sungai juga secara nasional.

h. Perlunya koordinasi dengan Bappeda Provinsi DKI Jakarta untuk penguatan kebijakan makro, salah satunya dukungan anggaran provinsi terkait program online monitoring. Bappeda sedang berupaya dalam pembentukan sistem informasi terpusat Provinsi DKI Jakarta yang isinya merupakan hasil dari dinas-dinas unit-unit lain di lingkungan pemerintah provinsi DKI Jakarta.

i. Perizinan pemasangan sistem online monitoring dengan cara mengirim surat ditujukan ke Menteri PU dan Perumahan Rakyat untuk ditindaklanjuti oleh Tim Rekomendasi Teknis di BBWSCC untuk dibahas dan diterbitkan izinnya.

j. Untuk menjamin sustainability dari program online monitoring maka perlu antisipasi kehandalan teknis sistem online monitoring itu sendiri terhadap kondisi lingkungan sungai Ciliwung, yaitu sistem keamanan dan pengamanan, penganggaran maintenance dan pengembangan peralatan, perlunya diterbitkan kebijakan dan regulasi khusus terkait alert sistem kualitas air yang menekan badan atau pihak-pihak pembuang limbah untuk membuat sistem online monitoring sebagai alat untuk pendeteksi yang bersifat preventif. Pada akhirnya keberhasilan program ini ke depan sangat ditentukan oleh keberhasilan masyarakat untuk dapat mengelola limbahnya sendiri dan meminimalkan kadar polutan yang dibuang ke badan sungai, sehingga dapat diperuntukkan untuk kepentingan masyarakat yang lebih luas, misalnya ekoturisme yang aman dan menarik minat wisatawan. 


\section{DAFTAR PUSTAKA}

1. P. Nugro Rahardjo (2015), "Kajian 5 Aspek Penting Dalam Rencana Penerapan Sistem Online Monitoring Kualitas Air Sungai Ciliwung", Prosiding "Gerakan Nasional Indonesia Bersih", Januari, Tahun 2015, ISBN: 978-602-1124-52-9.

2. P. Nugro Rahardjo (2016), "Kajian Aspek Peran Serta Masyarakat Dalam Aplikasi Sistem Online Monitoring Kualitas Air Sungai Ciliwung", Buku Bunga Rampai "Aplikasi Teknologi Lingkungan Dalam Perencanaan Pemulihan Kualitas Lingkungan", Oktober 2016, ISBN : 978-602-410-062-9.

3. Undang-undang Republik Indonesia No. 7 tahun 2004 tentang sumber daya air

4. Peraturan Presiden Nomor 33 tahun 2011 tentang Kebijakan Nasional Pengelolaan Sumberdaya Air

5. Peraturan Pemerintah Republik Indonesia No. 38 Tahun 2011 tentang Sungai

6. Peraturan Pemerintah No. 42 Tahun 2008 Tentang Pengelolaan Sumberdaya Air.

7. http://www.pu.go.id/uploads/services/201111-30-11-26-55.pdf

8. https://konservasidasciliwung.wordpress.co m/kebijakan-tentang-ciliwung/bbws-ciliwungcisadane/

9. https://konservasidasciliwung. files.wordpress .com/2013/09/sekapur-sirih-ciliwung-pakteguh.pdf 